\title{
Extranodular extension in sentinel lymph node-positive breast cancer might predict further initiation of completion axillary lymph node dissection
}

\author{
Kadri Altundag ${ }^{1}$ (D)
}

Received: 14 October 2018 / Accepted: 16 October 2018 / Published online: 20 October 2018

(c) Springer Science+Business Media, LLC, part of Springer Nature 2018

\section{Dear Editor,}

I want to congratulate Hennigs and their colleagues for their article [1] in which they investigated which patients with sentinel lymph node (SLNs)-positive breast cancer after breast conservation still received completion axillary lymph node dissection (cALND) in routine clinical practice. They reported that fewer removed SLNs, two tumouraffected SLNs, younger age, lower annual case volume per hospital, higher tumour grade, and lymphovascular invasion were associated with cALND. However, the authors did not take extranodular extension (ENE) of positive SLN into consideration as a variable for further cALND. One study evaluated he prognostic role of ENE in SLN-positive breast cancer patients in terms of overall and disease-free survival by conducting a systematic review and meta-analysis. They globally included 624 patients (163 ENE+ and 461 ENE-) with a median follow-up of 58 months. ENE was associated with a higher risk of both mortality and recurrence of disease [2]. In conclusion, ENE in SLN-positive breast cancer

Kadri Altundag

altundag66@yahoo.com

1 MKA Breast Cancer Clinic, Tepe Prime, Cankaya, 06800 Ankara, Turkey seems to be strongly associated with a poorer prognosis in breast cancer and might predict further initiation of cALND.

\section{Compliance with ethical standards}

Conflict of interest Kadri Altundag have no conflict of interest to declare.

Ethical approval This article does not contain any studies with human participants or animals performed by any of the authors.

\section{References}

1. Hennigs A, Köpke M, Feißt M, Riedel F et al (2018) Which patients with sentinel node-positive breast cancer after breast conservation still receive completion axillary lymph node dissection in routine clinical practice? Breast Cancer Res Treat. https:// doi.org/10.1007/s10549-018-5009-2

2. Nottegar A, Veronese N, Senthil M et al (2016) Extra-nodal extension of sentinel lymph node metastasis is a marker of poor prognosis in breast cancer patients: a systematic review and an exploratory meta-analysis. Eur J Surg Oncol 42(7):919-925 